\title{
Mature Cystic Ovarian Teratoma: A Study of 43 Congolese Cases
}

Henriette Poaty ${ }^{1 *}$, Dimitry Moudiongui Mboungou ${ }^{2}$, Yolande Voumbo Mavoungou ${ }^{3}$, Jean Jacques Candelier ${ }^{4}$, Jean Félix Peko ${ }^{2}$, Léon Hervé lloki ${ }^{5}$, Philippe Coullin 4 .

${ }^{1}$ Faculty of Health Sciences, Histology-Embryology and Genetic Laboratory, Marien Ngouabi University, Brazzaville, Congo

${ }^{2}$ Morbid Anatomy Service, CHU Brazzaville, Congo

${ }^{3}$ Faculty of Health Sciences, Department of Public Health, Brazzaville, Congo

${ }^{4}$ INSERM U1197, Hospital Paul Brousse, 94800 Villejuif, France

5Obstetrics and Gynecology Service, CHU Brazzaville, Congo

*Corresponding author: Henriette Poaty, Faculty of Health Sciences, Histology-Embryology and Genetic Laboratory, Marien Ngouabi University BP 2672, Brazzaville, Congo, Tel: 00242066865761, E-mail: henriettepoaty@gmail.com

Rec date: Jan 26, 2018; Acc date: Jan 30, 2018; Pub date: Feb 02, 2018

Copyright: @ 2018 Poaty $\mathrm{H}$ et al. This is an open-access article distributed under the terms of the Creative Commons Attribution License, which permits unrestricted use, distribution, and reproduction in any medium, provided the original author and source are credited.

\section{Abstract}

Background: The mature cystic ovarian teratoma (MCOT) is a common benign ovarian neoplasm in the world, most prevalent among women of childbearing age. It is a disease related to parental imprinting in which genome is exclusively maternal. The purpose of the study was to review the tumour features in Congolese patients in order to clarify its prevalence, and its histological forms and to report the eventual associated chromosomal anomalies described in literature.

Methods: It was a retrospective study of MCOT seen in University Teaching Hospital of Brazzaville for a period of seven years, and five DNAs previously extracted from five MCOT. Two antibodies: DLK1 and TIMP2 were also studied by immunohistochemistry (IHC).

The confirmed positive diagnosis was performed by Hematoxylin-Eosin method. The eventual presence of chromosomal anomalies was investigated by metaphasic Comparative Genomic Hybridization (mCGH) method. IHC analysis had permit to verify expression of paternal imprinted gene $D L K 1$ expression compared to maternal imprinted gene TIMP2.

Results: During the study period, a total of 215 cases of ovarian neoplasms have been seen, from which $20 \%$ $(43 / 215$ cases) with confidence interval $(\mathrm{Cl}) 95 \%=[14.7 \%-25.3 \%]$ were diagnosed MCOT. They represent $38.7 \%$ $(43 / 111$ cases) $($ IC $95 \%=[29.9 \%-48.1 \%])$ of all benign ovarian tumors and they account for $0.4 \%(43 / 10170)$ of all tumors diagnosed during the study period. The average age of patients having MCOT was 30.7 years with extreme ranging from 2 to 70 years. Cutaneous tissue was the most prevalent histological form. About IHC analysis, no staining was observed with mono-allelic paternal gene DLK1 contrasting with high TIMP2 staining of nuclear stem cells in the basal layer of the epidermis. Concerning $\mathrm{mCGH}$, no profile revealed chromosomal rearrangements.

Conclusion: The benign ovarian teratoma remains a common ovarian neoplasm in young Congolese women in reproductive age. The predominant skin tissue form signed the current called ovarian dermoid cyst. The $\mathrm{CGH}$ analysis in our study revealed that pathology is not associated with chromosomal anomalies, but some associations are described in literature.

Keywords: Teratoma; Ovarian dermoid cyst; Imprinted gene; Parthenogenetic tumour

\section{Introduction}

The mature teratoma is in general a benign tumour: cystic, solid or mixed mass that develops from totipotent germ cells or pluripotent somatic stem cell $[1,2]$. There exist various types of mature teratoma (ovarian, testicular, sacrococcygeal, mediastinal). A common form among the females is the mature cystic ovarian teratoma (MCOT), also called ovarian dermoid cyst as reported by Le Blanc, since 1831 or whether benign ovarian teratoma (BOT) $[3,4]$. The latter is known as parthenogenetic tumour, without paternal genome contribution, as result of paternal chromosomes lack [5].
In Europe, it is the most common ovarian neoplasm particularly among women of reproductive age, accounting for $95 \%$ of ovarian germ cell tumours [3]

Histologically, MCOT is made of mature somatic adult tissues and the incidence of malignant change is rare (1\% to $3 \%)$ and occurs mainly among postmenopausal women with predominance of squamous cell carcinoma ( $75 \%$ of cases) [6,7]. Differential diagnosis of MCOT includes epidermoid cyst (immature teratoma), less frequent, $1 \%$ of ovarian tumours. The latter is a small lesion, more prevalent among elderly women [8].

The MCOT can easily be identified by the following methods $[6,7]$ :

- The clinical examination which depends on the size of the tumour. The most common symptoms are abdominal pains with feelings of 
heaviness, increase in abdominal size, constipation, progressive dyspnea, dysuria, metrorrhagia, dyspareunia and pernicious. A vaginal touch reveals an adherente controlateral mass in uterus.

- Imaging evaluation such as abdominal X-ray and only an echography help to have a positive diagnostic in most cases. Scan and magnetic resonance imaging (MRI) confirm the diagnosis by an analysis of the tumour content [9].

- Biological tests include level of tumor markers: alpha fetoprotein, beta-human chorionic gonadotrophin ( $\beta-\mathrm{HCG}$ ), CA125, CA19-9, carcinoembryonic antigen and squamous cell carcinoma antigen $[3,9,10]$.

- Histopathological analysis confirms the diagnosis and immunohistochemistry (IHC) can reveal the malignant components.

The MCOT whose real cause still remains unknown is an ovarian pathology often diagnosed in Congo. In the context of causal research, the aim of the present preliminary study is to review the tumour features among Congolese patients, by specifying the prevalence and current histological forms, and to report the eventual associated chromosomal rearrangements (CNA) observed by metaphasic CGH (mCGH) method. We also search for expression of the paternal expressed $D L K 1$ gene compared to TIMP2 gene maternally expressed.

\section{Material and Methods}

It was a retrospective study and conducted for a period of seven years in University Teaching Hospital of Brazzaville (UTH-B).

\section{Materials}

The study was based on clinical files of MCOT (Table 1), derived from a series of Congolese ovarian neoplasms after ovarian cystectomy, with histopathology confirmation. We also report a preliminary analysis of DNA MCOT samples (BOT 1, 2, 3, 4 and 5). Two antibodies: $D L K 1$ (delta like homolog 1) paternally expressed and TIMP2 (Tissue inhibitor of matrix metalloproteinase 2) maternally expressed were examined in five MCOT (dermoid cyts).

\begin{tabular}{|c|c|c|c|c|c|}
\hline Case & Age (years) & Tumours & Site & Macroscopy and Microscopy & Conclusion \\
\hline 1 & 33 & $07 \mathrm{H} 124$ & RO & Black hair, skin tissue, hypertrophic sebaceous glands. & Dermoid cyst \\
\hline 2 & 45 & $07 \mathrm{H} 344$ & LO & $\begin{array}{l}\text { Sebum and hair. Bronchial epithelium, skin, thyroid and smooth } \\
\text { muscle tissues }\end{array}$ & MPT \\
\hline 3 & 6 & 07H393 & RO & Bronchial epithelium, smooth muscle, cartilage and neural tissues & MPT \\
\hline 4 & 56 & $07 \mathrm{H} 881$ & LO & Sebum, black hair. Nerve, adipose and bronchial tissues & MPT \\
\hline 5 & 43 & 07H1058 & RO & Sebum, black hair. keratin and others mucoid substance & Dermoid cyst \\
\hline 6 & $U$ & 07H1093 & RO & $\begin{array}{l}\text { Sebum and black hair. Calcified cutaneous tissue, hypertrophic hair } \\
\text { follicles }\end{array}$ & Dermoid cyst \\
\hline 7 & $U$ & $08 \mathrm{H} 136$ & OSNS & keratin and others mucoid substance & Dermoid cyst \\
\hline 8 & 63 & $08 \mathrm{H} 354$ & RO & Sebum and black hair. Keratin and others mucoid substance & Dermoid cyst \\
\hline 9 & 10 & $08 \mathrm{H} 583$ & LO & Smooth muscle, nerve, cartilage tissues and bronchial epithelium & MPT \\
\hline 10 & 24 & 08H917 & LO & $\begin{array}{l}\text { Bronchial epithelium, adipose tissue, chondroid, osteoid, } \\
\text { angiomatous, neural cells astrocytes }\end{array}$ & MPT \\
\hline 11 & 28 & $08 \mathrm{H} 1021$ & RO & $\begin{array}{l}\text { Sebum and black hair. Skin tissue, bronchial epithelium, du } \\
\text { cartilage et des muscles laisse. }\end{array}$ & MPT \\
\hline 12 & $U$ & $08 \mathrm{H} 1138$ & RO & Sebum and black hair. Nerve, adipose tissue, bronchial epithelium & MPT \\
\hline 13 & 10 & $08 \mathrm{H} 1173$ & LO & Sebum and hair. Epidermal tissue an follicle hair & Dermoid cyst \\
\hline 14 & $U$ & $09 \mathrm{H} 291$ & BO & $\begin{array}{l}\text { Bronchial epithelium, adipose, chondroid, osteoid, angiomatous } \\
\text { and nervous tissues. }\end{array}$ & MPT \\
\hline 15 & 42 & $09 \mathrm{H} 624$ & RO & Hair, Osteoid and epidermal tissues, follicle hair & Dermoid cyst \\
\hline 16 & 46 & $09 \mathrm{H} 688$ & BO & Epidermal tissue, follicle hair and teeth & Dermoid cyst \\
\hline 17 & 3 & 09H706 & LO & Black hair, sebaceous glands & Dermoid cyst \\
\hline 18 & 29 & $09 \mathrm{H} 863$ & LO & Hair, skin tissue & Dermoid cyst \\
\hline 19 & 24 & $09 \mathrm{H} 1154$ & LO & Skin tissue, sebaceous glands & Dermoid cyst \\
\hline 20 & 23 & $10 \mathrm{H} 763$ & LO & Hair. Keratin and others mucoid substance & Dermoid cyst \\
\hline 21 & 21 & $10 \mathrm{H} 769$ & $\mathrm{BO}$ & Cutaneous tissue, mucoid substance & Dermoid cyst \\
\hline
\end{tabular}




\begin{tabular}{|c|c|c|c|c|c|}
\hline 22 & 70 & $10 \mathrm{H} 1119$ & RO & Sebum and hair. Cutaneous tissue & Dermoid cyst \\
\hline 23 & 35 & $11 \mathrm{H} 199$ & OSNS & Sebum and hair. Epidermal tissue and hair follicle & Dermoid cyst \\
\hline 24 & $\mathrm{U}$ & $11 \mathrm{H} 332$ & LO & Sebum and hair. Skin tissue with various sebaceous glands & Dermoid cyst \\
\hline 25 & 28 & 11H352 & RO & Sebum and hair. Skin tissue. & Dermoid cyst \\
\hline 26 & $\mathrm{U}$ & $11 \mathrm{H} 1200$ & $\mathrm{RO}, \mathrm{RF}$ & Sebum and hair. Mixed tissue skin, bronchial and nervous tissue & MPT \\
\hline 27 & 33 & $12 \mathrm{H} 061$ & RO & Hair. Cutaneous tissue with various sebaceous glands & Dermoid cyst \\
\hline 28 & $\mathrm{u}$ & $12 \mathrm{H} 248$ & LO & Sebum and hair. Mixed tissue cutaneous and bronchial tissues. & MPT \\
\hline 29 & 37 & $12 \mathrm{H} 360$ & RO & Hair. Epidermal tissue, hair follicle, mucoid substance & Dermoid cyst \\
\hline 30 & 2 & $12 \mathrm{H} 429$ & SC, RO & Skin tissue. & Dermoi cyst \\
\hline 31 & 16 & $12 \mathrm{H} 1030$ & BO & Sebum and hair. Mixed skin tissue, bronchial and neural tissue & MPT \\
\hline 32 & 28 & $12 \mathrm{H} 1313$ & RO & Hair. Skin tissue & Dermoid cyst \\
\hline 33 & 55 & $13 \mathrm{H} 159$ & OSNS & $\begin{array}{l}\text { Mesenchymal tissue with tubular formation of cartilage and skin } \\
\text { tissue }\end{array}$ & MPT \\
\hline 34 & 39 & 13H1116 & OSNS & Sebum and hair. Skin tissue & Dermoid cyst \\
\hline 35 & 19 & $13 \mathrm{H} 1210$ & OD & $\begin{array}{l}\text { Hair and sebum. Mesenchymal tissue with tubular formations of } \\
\text { cartilage and cutaneous tissue }\end{array}$ & MPT \\
\hline 36 & $u$ & $13 \mathrm{H} 1243$ & LO & $\begin{array}{l}\text { Hair, teeth, sebum. Fibrous tissue, keratinized squamous lobules, } \\
\text { chondroid and calcified osteoid lobules }\end{array}$ & MPT \\
\hline 37 & 26 & $13 \mathrm{H} 1398$ & BO & Hair and sebum. Mixed skin tissue, bronchial and nervous tissues & MPT \\
\hline 38 & 17 & 13H1509 & LO & Sebum and hair. Epidermal tissue and hair follicle & Dermoid cyst \\
\hline 39 & 48 & $13 \mathrm{H} 1580$ & RO & Black hair, sebum, skin tissue & Dermoid cyst \\
\hline 40 & 27 & $14 \mathrm{H} 380$ & RO & Sebum and hair. Mixed skin and bronchial tissues. & MPT \\
\hline 41 & 20 & $14 \mathrm{H} 554$ & RO & Sebum and hair. Mixed skin tissue, bronchial and neural tissues & MPT \\
\hline 42 & 49 & $14 \mathrm{H} 595$ & BO & Skin tissue. Sebum and hair. & Dermoid cyst \\
\hline 43 & 20 & $14 \mathrm{H} 1456$ & RO & Sebum and hair. Mixed skin, muscle and nervous tissues. & MPT \\
\hline
\end{tabular}

Table 1: Mature cystic ovarian teratoma data.

\section{Methods}

The method was performed by two sorts of analyses on embedded paraffin blocks: Hematoxylin-Eosin (HE) staining and IHC. The analysis of DNA tumors samplings were performed by mCGH.

HE method had permitted the confirmation of histological diagnosis of all tumors. MCOT tissues were fixed in $10 \%$ formalin for 48 hours minimum and dehydrated. Then, they were included in paraffin blocks and conserved at room temperature. Tissues were cut into $4 \mu \mathrm{m}$-thick slices. The HE method was made according to the usual protocol.

IHC analysis from the Novolink Polymer ${ }^{\mathrm{m}}$ detection System Kit (RE71406, Novocastra) was used to detect proteins expression of the two imprinting genes (Oncogene Research Product, USA, Ref. IM11L) diluted to $1 / 100$. Epitope retrieval was performed in $10 \mathrm{mM} \mathrm{pH} 6$ citrate buffer for 45 minutes at $96^{\circ} \mathrm{C}$. After the usual steps, slides were incubated with primary antibody for 30 minutes at room temperature, followed by an extension overnight at $4^{\circ} \mathrm{C}$. After PBS standard rinsing, a post primary block followed by a Novolink polymer were applied for 30 minutes each, followed by two washings in PBSX1, by DAB revelation and by hematoxylin counterstaining.

mCGH technique is a molecular cytogenetic method which detects chromosomal rearrangements higher or equal to $5-10 \mathrm{Mb}$. It was to cohybridzed on normal human metaphase, normal DNA and MCOT DNA extracted from DNeasy tissue kit (Promega, reference 69504) labelled with fluorochromes of different colour $[11,12]$. Normally the fluorescence ratio between the two hybrids is proportional to the ratio of the number of copies of sequences of normal DNA and tumour DNA. The method highlights abnormal regions of chromosomal gains or losses. 


\section{Ethics approval}

The study requires the Ethics Committee's approval (Institutional Ethics Committee of Research on Health Sciences, No 305).

\section{Statistical analysis}

Data are medians with intervals. The confidence interval has been considered to $95 \%$. We used the Student's t-test with the SPSS 10 (SPSS statistics version 10.0).

\section{Results}

\section{Frequencies}

During the study period, out of a total of 10170 tumours diagnosed in UTH-B, the number of MCOT was 43 cases. All ovarian tumours (benign and malignant) were two hundred and fifteen (215), in which we noted 111 benign tumours and 104 malignant ovarian tumours.

The MCOT frequency compared to all ovarian tumours was $20 \%$ (43/215 cases) with confidence interval (CI) $95 \%=[14.7 \%-25.3 \%]$, and they represent $38.7 \%$ (43/111 cases) (IC $95 \%=[29.9 \%$ to $48.1 \%])$ of benign ovarian tumours. The prevalence MCOT, relative to all tumours was $0.4 \%$ ( $43 / 10170$ cases).

The most affected group (21 patients) was young women of childbearing age. But were also affected: children ( 7 patients) and menopausal women with over 45 years old ( 7 patients).

The average age of patients having MCOT was 30.7 years with extreme ranging from 2 to 70 years. In eight cases, age was not reported. Fourteen women of our series (32\%) were from the department of Central Basin. Others were from various regions.

Concerning the location, right ovarian implantation was predominant in $45.5 \%$ (20 cases). The left ovary was affected in $30.2 \%$ (13 cases). Bilateral involvement was observed in $13.9 \%$ (six cases). In 9.3\% (4 cases), the location was not specified. Coexistent ovarian teratoma with sacrococcygeal site and fallopian location was noted in two patients (26 and 30$)$.

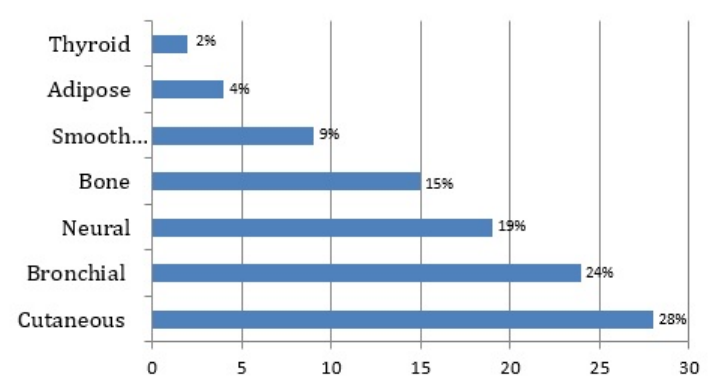

Figure 1: Graphic of MCOT histological forms. Note various somatic tissues found, derived from the three embryonic layers with preponderance of skin tissue.

\section{Histological distribution}

The microscopic distribution (Figure 1) of MCOT in order of frequency was: Firstly, one may observe cutaneous tissue in $28 \%$
(15/43 cases), followed by respiratory tissue in $24 \%$ (mainly bronchial, 13 cases), neural tissue 19\% (10 cases), bone tissue 15\% (8 cases), smooth muscles tissue 9\% (5 cases), adipose tissue (4 cases) and one case of thyroid tissue. Concerning children, unitissular skin tissue was predominant (4/7 cases). All those tumours were benign.

\section{mCGH and IHC}

All mCGH profiles lacked chromosomal abnormalities. IHC revealed no expression of $D L K 1$ protein in all MCOT contrasting with high staining of TIMP2 in stem cells nuclei of the basal layer of epidermis (Figure 2).

\section{Discussion}

\section{Epidemiology}

Teratoma frequencies found in our study were in concordance with data review [13-16]. The most affected group was women in reproductive age, but children and menopausal women were also concerned.

The prevalence rate of $20 \%$ of all ovarian neoplasms and the mean age of 31 years were in line with data of literature. Indeed, MCOT accounts for $10 \%$ to $20 \%$ of all ovarian adult neoplasms with approximately mean age of 27 years $[4,14,15]$ and it represents $60 \%$ to $70 \%$ of all benign ovarian tumours $[3,16]$.

The predominance of disease in women coming from the region of the central basin has probably an etiological significance that may be related to the proximity of the region with UTH-B, existence of nutritional deficiencies in patients or patients' parents or whether genetic predisposition. Indeed in another parallel tumour related to parental imprinting: hydatidiform mole, androgenic tumour in which there is no maternal whole genome; except for the causal imprinting gene NLRP7 (NALP7) involved in familial recurrent molar pregnancies, dietary deficiencies (particularly vitamins A and B9) are indexed [17]. The latter would cause abnormalities in genome, particularly in altered imprinting genes which can build the nest in the development of hydatidiform mole, which can lead to cancer $[11,12]$.

The data about location show than right ovarian implantation was the most common teratoma site. Teratoma was associated with fallopian tube site in one young woman (patient 26) and sacrococcygeal region in child of two years (patient 30). These two latter associations are extremely rare [14]. In reality teratomas are able to develop anywhere in the body, but ovaries and scrotal regions are the common locations $[18,19]$.

Embryologically, it is known that gonadal and extragonadal teratomas location follow mostly normal territories of origin and migration of totipotent primordial germ cells [20]. During normal embryogenesis, the primordial germ cells appear at three weeks of embryonic development at yolk sac level, near allantoic diverticulum [21]. Then, they migrate at the fourth week of embryonic development along the primitive intestine wall of embryo towards gonads in formation [21]. These territories are: allantoic diverticulum, urachal portion that explain the midline location preferentially sacrococcygeal location in children; but also ovaries, testes and root of the mesentery.

According to literature data, three possible theories explain the origin and the location of these tumors [22]: 
- First, teratomas can derive from the totipotent germ cells which can have also aberrant migration which is the cause of extragonadal sites, more diagnosed in infancy.

- Secondly, they derive from the primitive node during three weeks of embryonic development.

- The last theory is that the tumor arises from an incomplete twinning [22].

Usually, teratomas are found in sacrococcygeal area in 57\% of cases among children $[4,19]$, that account for 1 per 21,700-35,000 live births $[22,23]$. That form is rare among adults (incidence of $1: 87,000$ ) [9]. Gonadal location (ovary and testis) second common site represents $29 \%$ [4]. The uncommon locations are in fallopian tube (only 70 cases reported in literature), in uterine corpus or into the endocervix $[14,15]$ The sites that occur on craniofacial and neck regions $(2-5 \%$ of all paediatric teratomas), oral cavity (1.6\%), mediastinum or abdominal wall are also rare $[13,18,24]$.

In our study ovarian teratoma were very often unilateral (86\%) and rarely bilateral (13.9\%) as observed in literature and the complications type spontaneous rupture or torsion were not observed $[4,13,25]$.

Concerning histopathological features, originally, the MCOT derived from a unique germ cell, undifferentiated, totipotent, able to give rise to mature somatic tissues derived from the three embryonic layers: ectoderm, endoderm and mesoderm [5,24-OMIM \#166950]. Thus, it will give rise to a complex pluritissular teratoma (in girls) that would be transformed in a unitissular mature teratoma with increasing age.

Microscopically, our MCOT series were mostly consisted of ectodermal tissues origin and uni-tissular in 58.1\% (25 cases) with predominance of cutaneous tissue and its annexes: skin, black hair, sebaceous glands (Figures 2A and B). The pluritissular MCOT estimated at $41,9 \%$ ( 18 cases) also contained $60.46 \%$ of skin tissue. This preponderance of skin tissue explains the name of dermoid ovarian cystic commonly attributed to MCOT. Various tissues derived from the three embryonic layers were observed (Figure 1): ectoderm, $47 \%$ (skin and nervous tissues), endoderm, 26\% (bronchial and thyroid tissues), and mesoderm layer 26\% (bone, muscle and adipose tissue). These results reflect the various histological forms of somatic tissues usually cited in reviews.

According to literature data, the most common structures are ectodemal tissues. Indeed, skin tissue and its annexes are almost always present (in 31\% of cases): black hair, hair follicles, sebaceous glands, gingival epithelium and teeth. The neural tissues (in $38 \%$ of cases) with its components are often: cerebellar cortex, ependymal, meninges or sympathetic ganglia. Endodermal tissues are in the majority of cases respiratory tissue (48\%): bronchial epithelium; but, are also present in intestinal tissue (7-13\%), salivary and thyroid tissues (3-14\% of cases) $[1,16,20]$. Mesodermal tissues are: bone, cartilage, muscle, adipose tissue (67\% to $75 \%$ of cases) and conjunctival tissue as adipose tissue [7].

For information purposes, the kidney, pituitary or trophoblastic tissues are only observed in malignant teratoma.

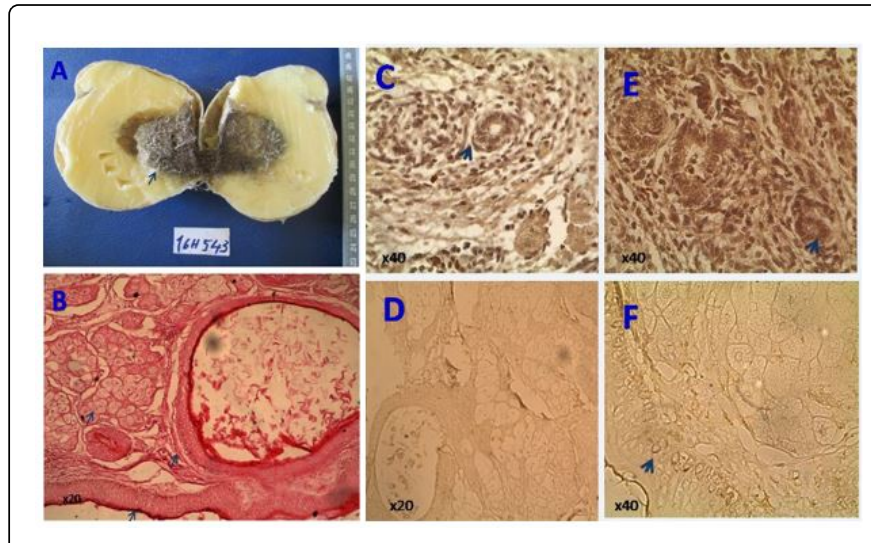

Figure 2: MCOT with HES and IHC DLK1, TIMP2 proteins. A) Macroscopic image of Ovarian dermoid cyst with black hairs. B) Microscopic image (HES) of ovarian dermoid teratoma: skin tissue with sebaceous glands, hair follicles, sweat gland in the subepithelial stroma and malphigium epithelium. C) $D L K 1$ and normal fetal ovary, 11 weeks: $(+++)$ high staining of nuclei cells in primordial follicles. D) MCOT and DLK1: (-) no tissular labelling. E) TIMP2 and normal ovary: (+++) high staining of nuclei cells in primordial follicles, stromal cells and fibers. F) MCOT and TIMP2: $(++)$ staining of nucleistem cells in basal layer cells of epidermis. No staining of superficial layers of keratinocyts.

Concerning genetic characteristics: in general, MCOT are sporadic diseases, but rare familial forms inherited have been reported [26]. In the latter, bilateral teratoma can be observed in $10 \%$ to $25 \%$ [OMIM \#166950]. MCOT is a genetic disorder disease in which the whole paternal genome is absent [5,27]. The disease is linked to parental imprinting: paternal imprinted genes having a monoallelic paternal expression are not expressed. Conversely, all maternal genes are expressed. But, genomic imprinting mechanism is known to prevent parthenogenesis [28]. DLK1 (delta-like 1) is a monoallelic paternal imprinted gene mapped on $(14 \mathrm{q} 32.2<100,26-101,22>)$. It is a tumour suppressor gene, also known as fetal antigen (FA1). It acts in $\mathrm{NOTCH}$ signaling pathways and it is a pre-adipocyte factor 1 (Pref-1) due to its ability to inhibit the differentiation of pre-adipocytes [GRCh38/ hg38/2013, OMIM\#176290]. It regulates the differentiation of various tissues (as hematopoiesis) through other cellular mechanisms [28]. The normal ovarian cells express DLK1 protein (Figure 2C), while no labelling is observed in ovarian dermoid cyst cells (Figure 2D). Those data are the result of deficiency in paternal imprinting. On the other hand, TIMP2 [GRCh38/hg38/2013, OMIM\#188825] monoallelic maternally expressed gene located on $(17 \mathrm{q} 25.3<74,36-74,43>)$, suppressor of tumor, presented a nuclear staining in both undifferentiated normal ovarian cells (Figure 2E) and ovarian dermoid cyst stem cells (Figure 2F). Those results show (as known) than TIMP2 and also $D L K 1$ are stem cell markers.

It is usually accepted that MCOT may be homozygous (HZ) or heterozygous (HTZ) (Figure 3) [2]. When HZ (65.2\% of cases), it has been developed through a single germline stem cell derived from meiosis I (MI) after a failure of meiosis II (MII) or after endoreduplication of mature oocyte (Figures 3B and 3D) $[29,30]$. When HTZ (34.8\% of cases), it comes from the mitotic division of oogonia or a cell in which meiosis I has failed (Figure 3C) [2,29-31]. In 
95\% of cases, karyotype is diploid, 46, XX and CGH profiles are normal $[1,2]$.

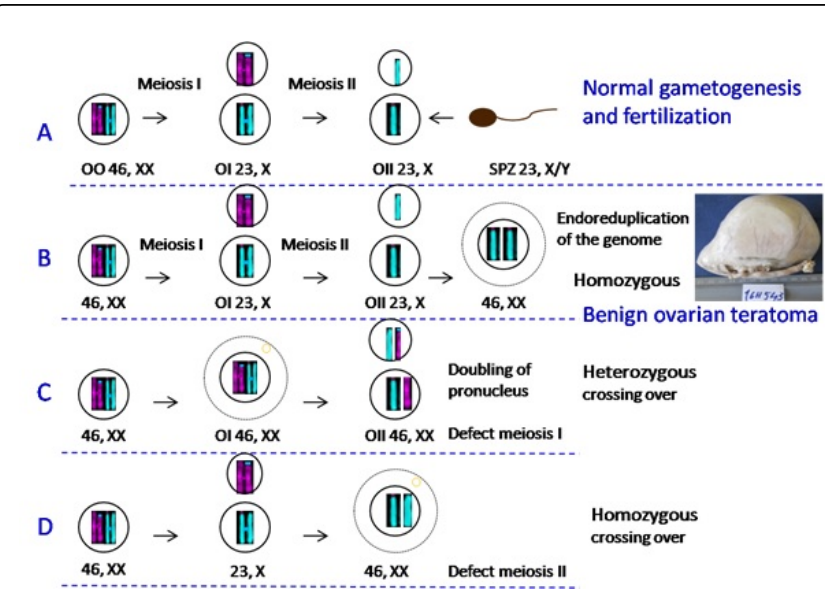

Figure 3: Possible mechanisms for the formation of the benign ovarian teratomas. A. Normal gametogenesis. B, C and D. Abnormal gametogenesis. Teratomas originating from oogonia $(\mathrm{OO})$, primary oocyte (OI), secondary oocyte (OII) or mature oocyte.

\section{Conclusion and Reasoning}

In our DNA analysis, the CGH profiles were normal. These data do not allow a conclusion because the DNA sampling was too small and mCGH, although reliable, does not detect chromosomal rearrangement below $5 \mathrm{Mb}$. In a next work we will use array-CGH analysis which is a more efficient and desirable method. However, in approximately $7 \%$ of cases, chromosomal disorders in teratoma tissues observed by karyotype and CGH have been described such as: deletion, trisomy, triploidy and mosaïcism [27,30]. Trisomy can concern the chromosomes 1q, 3, 7, 8, 15, 21 and chromosomes 12, 13 $[27,30]$. Fetal congenital anomalies due to the meiotic errors as Patau syndrome or Down syndrome can also be associated with teratoma in child $[2,23]$.

The benign ovarian teratoma is the most benign ovarian tumor observed among Congolese women of childbearing age. The epidemiological profile and histological features are similar to that found in literature. The CGH analysis in our study revealed that pathology seemed not to be associated with chromosomal anomalies. But rare associations are described in literature. And, finally, the prevalence of the disease in women native to one region has probably a significance that suggests a new study mainly focused on patient dietary habits and a genetic predisposition.

\section{What is already known on this topic?}

It is the most common ovarian worldwide neoplasm among women of reproductive age.

\section{What this study adds?}

It the first study that gives details on benign ovarian teratoma frequencies to Congo Brazzaville.

\section{Declarations}

\section{Competiting interests}

None.

\section{Fundings}

This work was not funded by any organization.

\section{Authors' contributions}

DB, HP, PC and JJC: Performed study and analyzed the data.

LHI and JFP: Contributed reagents and materials.

YYVVM: Statistical analysis.

HP: Designed study and write the paper.

\section{Acknowledgements}

We are especially grateful to Dr. Benjamin Evayoulou for supervising the English text.

\section{References}

1. Ulbright TM (2005) Germ cell tumors of the gonads: a selective review emphasizing problems in differential diagnosis, newly appreciated, and controversial issues. Mod Pathol 18: S61- S79.

2. Parrington JM, West LF, Povey S (1984) The origin of ovarian teratomas. J Med Genet 21: 4-12.

3. Ulkumen BA, Goker A, Pala HG, Ordu S (2013) Abnormal elevated CA 19-9 in the dermoid cyst: A sign of the ovarian torsion? Case Reports in Obstet Gynecol 2013: 860505.

4. Khanna S, Srivastava V, Saroj S, Mishra SP, Prakash S, et al (2012) An unusual presentation of ovarian teratoma: A case report. Case Rep Emerg Med 2012: 845-198.

5. Linder D, McCaw BK, Hecht F (1975) Origine parthénogénétique des tératomes ovariens bénins. N Engl J Med 292: 63-66.

6. Moghaddam Y, Lindsay R, Tolhurst J, D Millan, Siddiqui N (2013) A case of sebaceous carcinoma arising in a benign cystic teratoma of the ovary and review of the literature. Scottish Medical Journal 58: 18-22.

7. Ye L, Wang J, Liu D, Ding G, Cao L (2012) Management of giant ovarian teratoma: A case series and review of the literature. Oncol Letters 4: 672-676.

8. Kondi-Pafiti A, Filippidou-Giannopoulou A, Papakonstantinou E, Iavazzo C, Grigoriadis C (2012) Epidermoid or dermoid cysts of the ovary ? Clinicopathological characteristics of 28 cases and a new pathologic classification of an old entity. Eur J Gynecol Oncol 33: 479-483.

9. Al-Essa A, Malik TA, Baghdadi MK, El-Tayeb AA (2004) Adult sacrococcygeal teratomas. Saudi Med J 25: 367-369.

10. Var T, Tonguç EA, Ugur M, Altinbas S, Tokmak A (2012) Marqueurs tumoraux du panneau et la taille des tumeurs de l'ovaire dermoïde tumeurs en âge de procréer. Bratisl Lek Listy 113: 95-98.

11. Poaty H, Coullin P, Peko JF, Dessen P, Diatta AL, et al (2012) Genomewide high-resolution aCGH analysis of gestational choriocarcinomas. PLoS One, 7: e29426.

12. Poaty H, Coullin P, Leguern E, Dessen P, Valent A, Afoutou JM, et al. (2012) Cytogenetic studies of hydatidiform moles and gestational choriocarcinoma. Bull Cancer 99: 827-843.

13. Yaka M, Ehirchiou AK, Alkandry S, Zentar A (2015) Kyste dermoïde géant de la paroi abdominale: une observation rare. Pan African Medical Journal 21: 131. 
Citation: Poaty H, Mboungou DM, Mavoungou YV, Candelier JJ, Peko JF, et al. (2018) Mature Cystic Ovarian Teratoma: A Study of 43 Congolese Cases. Hereditary Genet Curr Res 7: 192. doi:10.4172/2161-1041.1000192

Page 7 of 7

14. Baek J (2016) Synchronus occurrence of mature cystic teratoma of the fallopian tube and ovary: A case report. Oncology Letters 12: 911-914.

15. Ohshima K, Umeda A, Hosoi A, Yamamoto T, Munakata S (2015) Mature cystic teratoma in Douglas pouch. Case Rep Pathol 2015: 202853.

16. Ki EY, Jang DG (2016) Rare case of complete colon structure in mature cystic teratoma of the ovary in menopausal woman: A case report. BMC Women's Health 16: 70.

17. Coullin P, Diatta AL, Bouffetal H, Feingold J, Leguern E, et al (2015) The involvement of the trans-generational effect in the high incidence of the hydatidiform mole in Africa. Placenta 36: 48-51.

18. Sahoo NK, Choudhary AK, Srinivas V, Tomar K (2015) Dermoid cysts of maxillofacial region. Med J Armed Forces India 71(Suppl 2): S389-s394.

19. Asdrubal F, Carlos G, Antonio FF (2004) Sacrococcigeal teratoma: A report of three cases. Neuropsiquiatr 62(2A): 334-338.

20. Philippe E, Charpin C (1992) Tératome kystique bénin de l'ovaire. Pathologie gynécologique et obstétricale. Masson. pp. 191-193.

21. Mitchell B, Sharma R. (2005) Embryologie: Last edition. Elsevier, Paris.

22. Sharma S, Gupta DK, Laberge JM, Lakhoo K (2007) Teratomas. globalhelp.org/Pedsurgeyafrica Chap 103. pp. 601-604.

23. Kasulelubala T, Mukuku O, Shongo PM, Mutombo MA, Lubala N, et al (2015) Sacroccocygeal teratoma in female newborn with clinical features of trisomy 13: a case report from Central Africa. International Med Case Report Journal 8: 333-336.

24. Ramesh P, Suman T, Sushana M (2015) Nature nasopharyngeal teratoma in a child. Case Report Otolaryngol 2015: 515474.
25. Gargano G, De Leonardis A, Perrotti P, Izzi G, Racanelli A, et al. (1990) Ovarian bilateral cystic teratomas: Diagnosis and therapy in a young woman. Clin Exp Obstet Gynecol 17: 37-42.

26. Gopal M, Turnpenny PD, Spicer R (2007) Hereditary sacrococcygeal teratoma--not the same as its sporadic counterpart! Eur J Pediatr Surg 17: 214-216.

27. Amiel A, Atzmon H, Klein Z, Kidron D, Gaber E, et al. (2003) Application of comparative genomic, hybridization technique for detection of chromosomal aberration in begnin teratoma cystic. Cancer Genet Cytogenet 144: 73-75.

28. Schneider G, Sellers ZP, Ratajczak MZ (2016) Parental imprinted genes regulate hematopoiesis-new evidence from the Dlk1-Gtl2 locus. Stem Cell Investig 3: 29.

29. Dahl N, Gustavson KH, Rune C, Gustavsson I, Pettersson U (1990) Tératomes ovariens bénins. Une analyse de leur origine cellulaire. Cancer Genet Cytogenet 46: 115-123.

30. Surti U, Hoffner L, Chakravarti A, Ferrell RE (1990) Génétique et biologie des tératomes ovariens humains. L'analyse cytogénétique et le mécanisme d'origine. Am J Hum Genet 47: 635-643.

31. Wang C, Lai YC (2016) Genetic analysis results of mature cystic teratomas of the ovary in Taiwan disagree with the previous origin theory of this tumor. Hum Pathol 52: 128-135. 